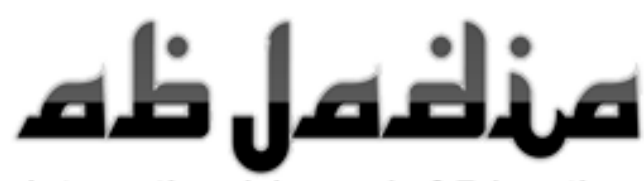

International Journal of Education

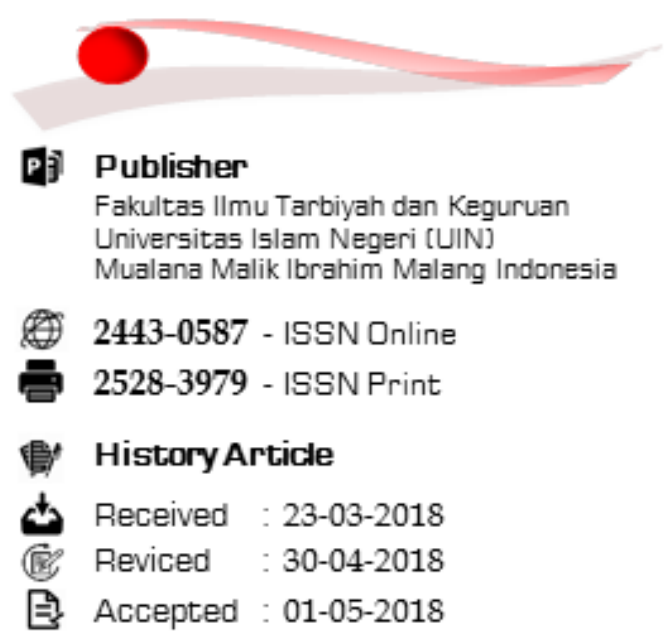

\subsection{0/abj.r3i1. 5939}

http://ejournal.uin-malang.ac.id/index.php/ abjadia/article/view/5939

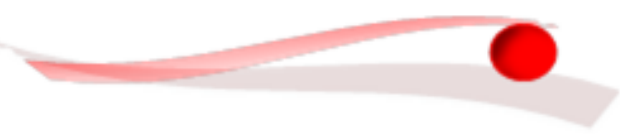
Q Zainul Mustofa
I. Indonesia
(2) SMK Al Munawwariyyah
Q Anik Asmichatin
I. Indonesia
3 SMAN 1 Kertosono
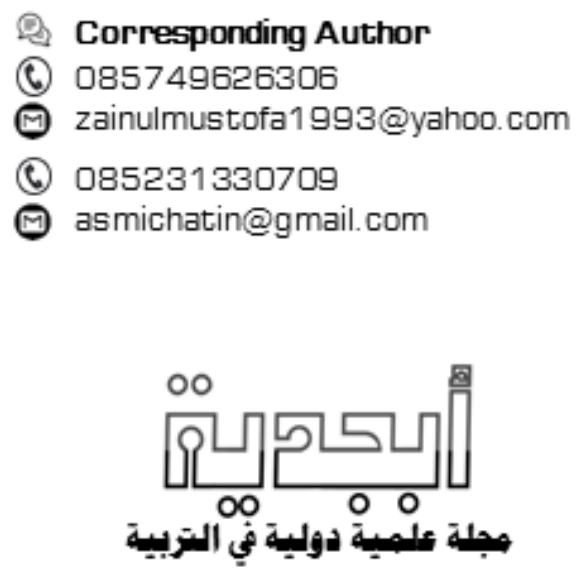

Zainul Mustofa, Anik Asmichatin

Indonesia

\section{MODELING INSTRUCTION TO PROMOTE STUDENT'S UNDERSTANDING OF SYSTEM AND MODEL OF SYSTEM OF MECHANICAL ENERGY}

\section{貿" Abstract}

Understanding of system and model of the system are necessary for conducting an analysis of scientific phenomena. One concept in science that requires system is energy. This research aimed to understand how modeling instruction promoted increasing student's understanding system and model of a system on mechanical energy material. Research was conducted on 30 students of MIA at SMAN 1 Kertosono. The result showed that student's understanding of the system and model of the system increased significantly. Series of learning in class showed that at every meeting session, student skill increased from novice to expert. They were able to show how important the system explain the mechanism of energy transfer were. Average N-gain 0.32 (medium category) indicated that modeling instruction was good enough to promote student understanding of the system. Moreover, any misconception about energy was able to prevent and overcome by this learning. By learning, student's skill to solve new problem had changed approaching expert problem solver.

Modeling Instruction, System and Model of System, Energy

Citation: Zainul, M., \& Asmichatin, A. (2018). Modeling Instruction to Promote Student's Understanding of System. Abjadia: International Journal of Education, 3(1), 17-29. 


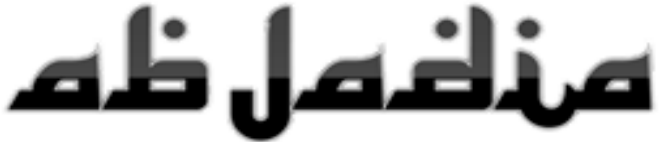 International Journal of Education}

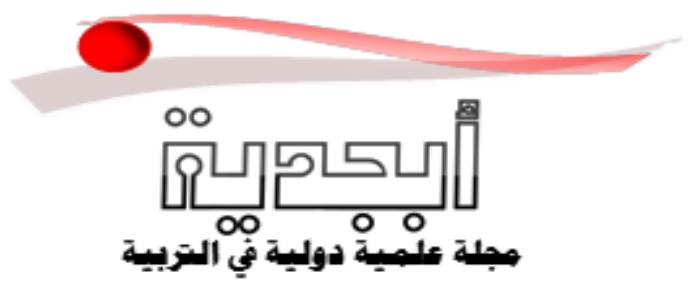

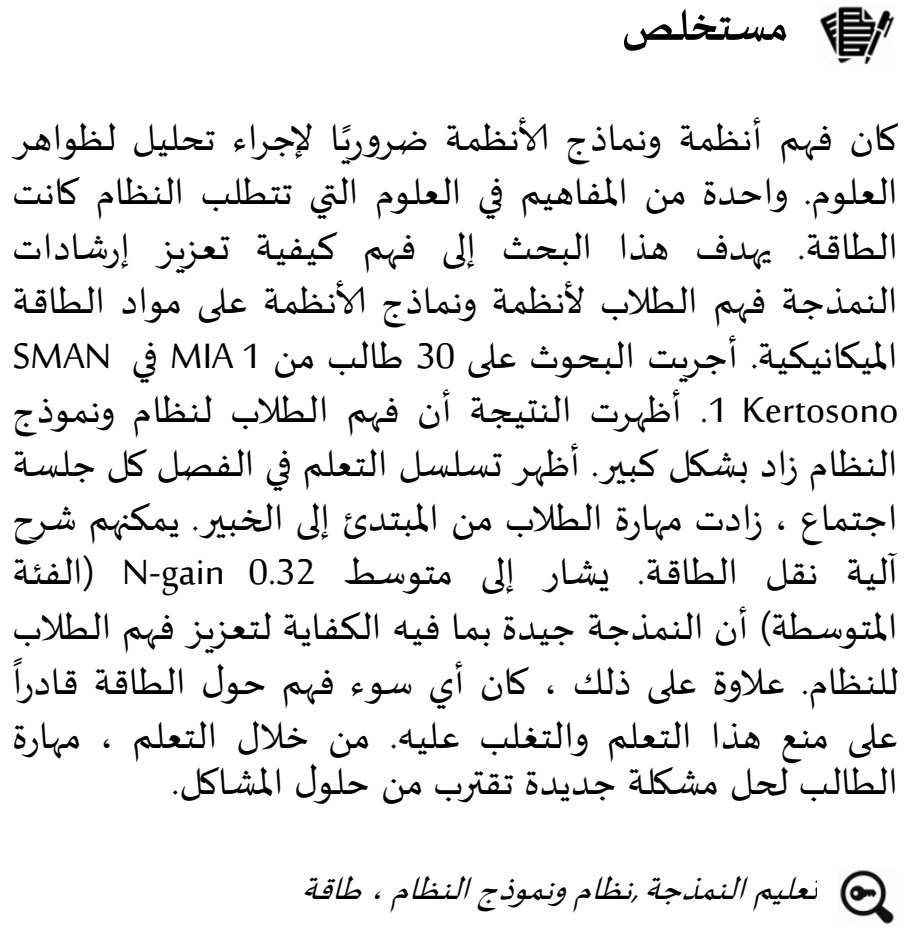

\section{(C) INTRODUCTION}

The main goal of learning and teaching science is to ensure students have some appreciation in science and possess good scientific literacy when engaging in their everyday lives (NRC, 2012). To attain the goal, many kinds of research have been conducted since a decade ago to enhance scientific literacy. Scientific literacy has a role to support individual to make a decision, solve a problem, increase scientific attitude and skill (Fakhriyah et al., 2017). Scientific literacy also became a key of competence in preparing individual using knowledge and information to understand any challenge of life (Purwani et al., 2018).

Preparing natural science student on increasing scientific literacy skill is the main goal of 2013 curriculum in Indonesia. It is corresponding with the characteristic of natural science observation that put everyday phenomena as a study object. Observation of phenomena in science must use a barrier area under study to increase the quality of the study. It showed that involves a system and environment as model of phenomena were a necessity. Furthermore, models and modeling were recognized as one of the important aspects of science and scientific literacy (Akerson et al., 2011; Develaki, 2016; NGSS, 2013).

Systems and model of the system are a crosscutting concept of science and engineering. The role of the system is very important to create a high-quality analysis of phenomena or problems. Scientific models are used not only as learning tools but also as representations and scenarios of abstract concepts and as consensus models of scientific theories (Karpin et al., 2014; Treagust et al., 2002). Models can be valuable in 
predicting a system's behaviors or in diagnosing problems or failures in its functioning, regardless of what system is being examined (NRC, 2012). So that, the skill of determining systems and create a model of the system is notable.

One of the phenomena on natural science that must be explained by system and environment is energy. Energy can't be defined only by a word but must be explained by a model of system and environment. Energy is a key quantity of system under study that easier to be an analysis of a phenomenon. While any single physical system can be analyzed and understood without resorting to energy, this construction provides a very big range of phenomena across many domains using the same perspective (Constantinou \& Papadouris, 2012). It means that energy analysis is easier than another analysis to understand phenomena in everyday lives.

Any research about energy showed that student can't explain perfectly about transfer energy, energy dissipation, and energy conservation. For examples: research by Mustofa et al. (2016) showed that most students had not understood about work and energy, Dalaglioglu et al. (2015) showed that most students in eleventh grade have a misconception about energy. This predicting problem is caused the less understanding of system and system models under study when they analysis energy on phenomena that be given.

One model of learning that facilitate students to determined systems and create a model of a system is modeling instruction. Modeling instruction is explicitly designed of model learning that engages students in scientific practices including build model, validate it, and revision better model (Brewe et al., 2009). Modeling Instruction is built based on the theory of cognitive development from Jean Piaget that said in learning, a student will process a situation through assimilation and accommodation (Arends, 2012; Slavin, 2006). Modeling Instruction is an integrated model learning that combines building model and utilizes the model to solve new problems. These aspects were developed in two steps: model development and model deployment (Jackson et al., 2008). Modeling instruction emphasized model development based on inquiry and used multiple representations. Modeling instruction not only effectively teach any physics concepts (Jackson et al., 2008), but also increase student participation in class and help a student to understand physics based on expert viewpoint (Brewe et al., 2009).

Based on any explaining about the strengthening of modeling instruction and a suitable model of learning for the student, this research focuses on how modeling instruction can promote student understanding about system and model of systems on mechanical energy. Therefore, in this paper have one main goal for proving how effective of modeling instruction to enhance student's understanding on mechanical energy. Futhermore, for supporting the main goal and understanding student's knowledge changing, an description of every session learning in class was explained.

\section{[Q] RESEARCH METHOD}

This research is a practical action research (PAR). This research aimed to understand how modeling instruction promotes students understanding of systems and system models on mechanical energy. In this research, we only used one cycle in one 
chapter. This cycle included: develop an action plan, identify an area focus (work and energy), collect data, and analyze and interpret data. Research conducted on the Senior high school of Kertosono, Nganjuk, Indonesia. The subject consists of 30 students grades XI MIA 1. Research conducted on even semester on academic year 2016/2017.

The research procedure consisted of three stages. They were diagnostic (pretest), implementation plan and posttest. In pretest and posttest, students understanding about energy problem were addressed. Then, an implementation plan, teacher applied modeling instruction to facilitate student's process learning in class. In modeling instruction, the teacher teaches students to build a model, validate it, and revise it based on any proof in the experimental session.

The instrument that used in this study was a rubric. Rubric consisted of three aspects, included: recognized problems (RP), determined solution based on system (DS), and completed solution based on a model of systems chosen (CS). Based on two rater analysis rubric result of $d$ cohen-kappa are 0,872 for the first aspect, 0,945 for the second aspect, and 0,974 for the last aspect. The result of a reliability test of Cronbach alpha was 0,68 (reliable). Besides using the instrument for analysis students understanding about system and model of a system, observation in class activity also was done.

Research question answered through analysis of students answer about the questions. The score of students were analyzed by the descriptive statistic of $\mathrm{N}$-gain (Hake, 1998) to see how big the changing of student skill on solving a new problem by system analysis model. Beside it, analysis about students plot of thinking when he solved the problems also conducted. To support the data, observation result, field notes and worksheet group were described qualitatively. The qualitative and quantitative analysis used to understand more deeply quantitative finding.

\section{FINDINGS \& DISCUSSIONS}

\section{Learning Activity on Subtopic Work and Work-Kinetic Energy Theorem}

Learning activity goal was directed to facilitate students building concepts: (1) work were caused by force; (2) work were one of energy transfer mechanism between system and environment; (3) work from the environment to the system caused changing of the kinetic energy of the system. Sequence activity in class is displayed in picture 1 .

Learning begins by displaying three incidents in everyday life to uncover students understanding about what work was. Based on activities, it appeared that work is force dot product with displacement, but students hadn't understood perfectly about what happens with work. To facilitate modeling of work, a simple experiment conducted. By doing an experiment, students analyzed data and success made a model of work $W=\vec{F} \cdot \vec{s}=|\vec{F}||\vec{s}| \cos \theta$. Classically, teacher facilitate students to create a model that involving manipulate of model of work become $W=\Delta E k$. Together with the teacher, students interpreted that work was energy transfer mechanism between system and environment. If work is positive, it means that energy transfer from the 
environment to the system that cause increasing kinetic energy and vice versa. This activity was called model development.

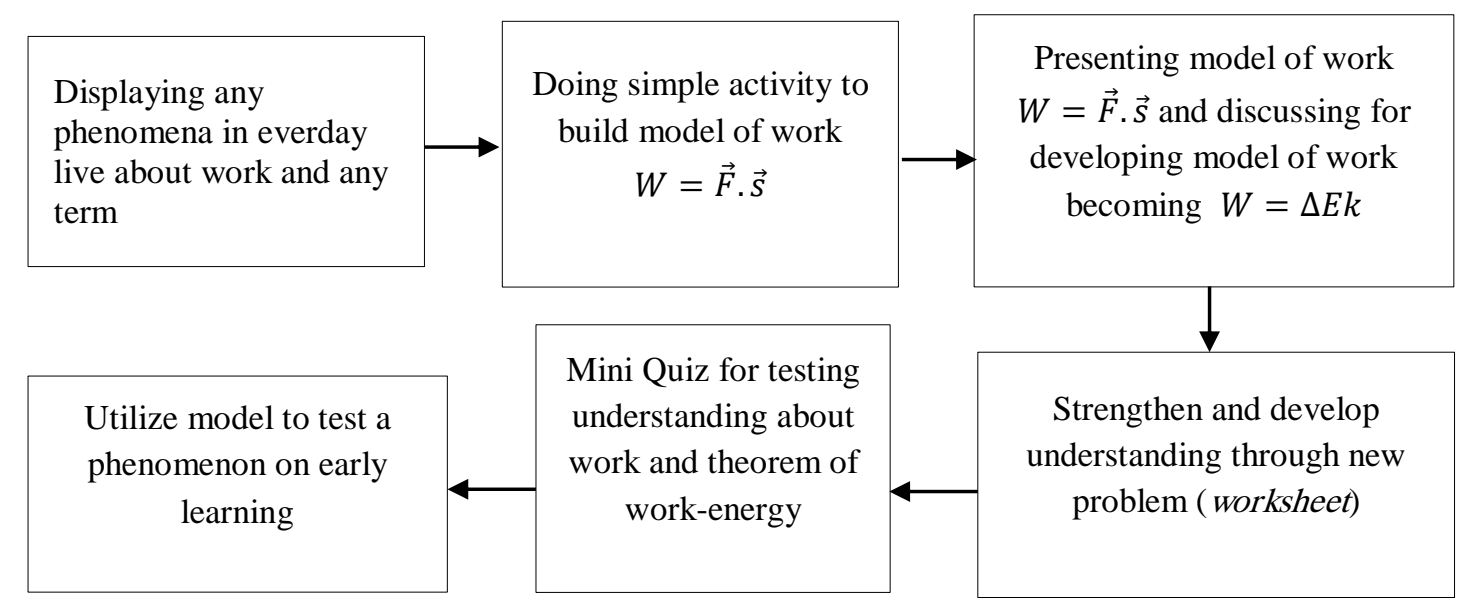

Picture 1. Sequence Activity of Learning of Work-Energy Theorem

Then students continue to model deployment. In this activity, every group asked to solve a new problem based on a model of work-kinetic energy that they built before this situation. This activity used to validate and strengthen the model that they built in the previous activity. A problem which is given was listed in picture 2 .

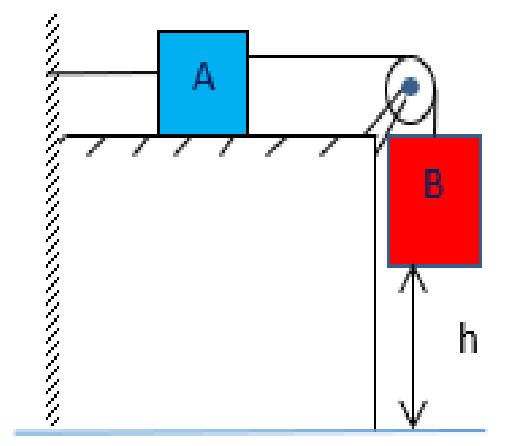

The system of two beams with different mass was tied with a rope lik the picture. If the hook to the wall is cut off, two beams move at the same speed. If it was known that mass $\mathrm{A}$ was $2 \mathrm{~kg}$, and mass $B$ was $3 \mathrm{~kg}$, coefficient of friction was 0.25 , the height was 1 meter, and mass of rope is neglected.

$h$ What is the speed of beam $B$ when it reached the ground?

Picture 2. New Problem about Model of Work

Based on student discussion result had been found any finding. One of the interesting findings was a characteristic way of solving a problem. Students group discussion result indicated that they hadn't used the model effectively. Most of the groups that used declarative knowledge couldn't explain the characteristic of energy by model. Although, they answered was true, they had not been able to explain energy transfer between system and environment exactly. In picture 3 appear that they began with determining any force then continued using Newton Law II. They used a limiting strategy by involving surface information based on phenomena (Chi, 1989; Docktor \& Mestre, 2014). In solving a problem, they ever used a Rolodex equation matching strategy for choosing what variable was known and unknown (Ogilvie, 2009). Its mean that in the first meeting they had not changed their strategy of classical solving problem. 


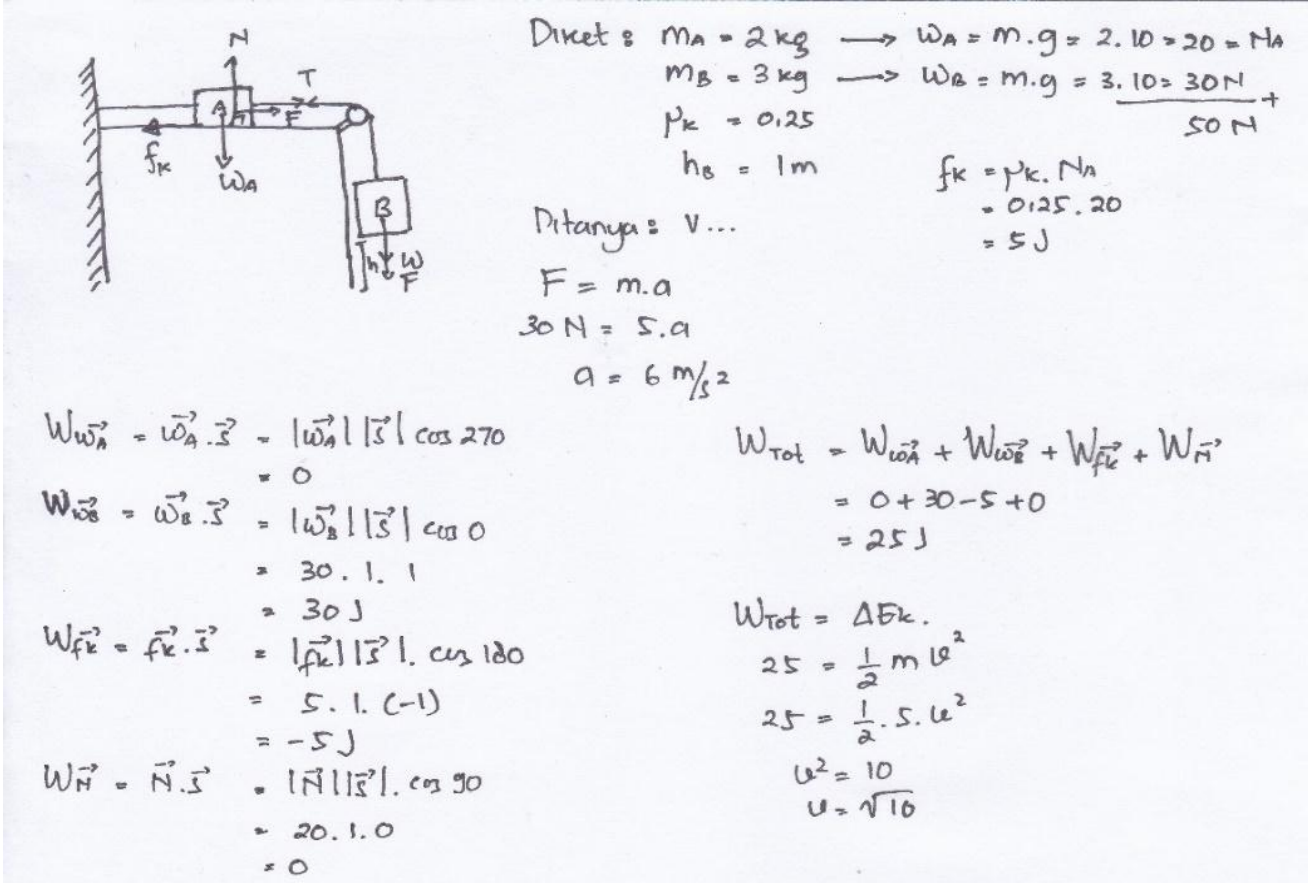

Picture 3. Students Group Answer for first new problem

\section{Learning of Potential Energy of System}

The Focus of this session was facilitated students on (1) understanding that potential energy is interaction result on a system and (2) finding the relationship between potential energy and work. Outline learning can be seen on Picture 4.

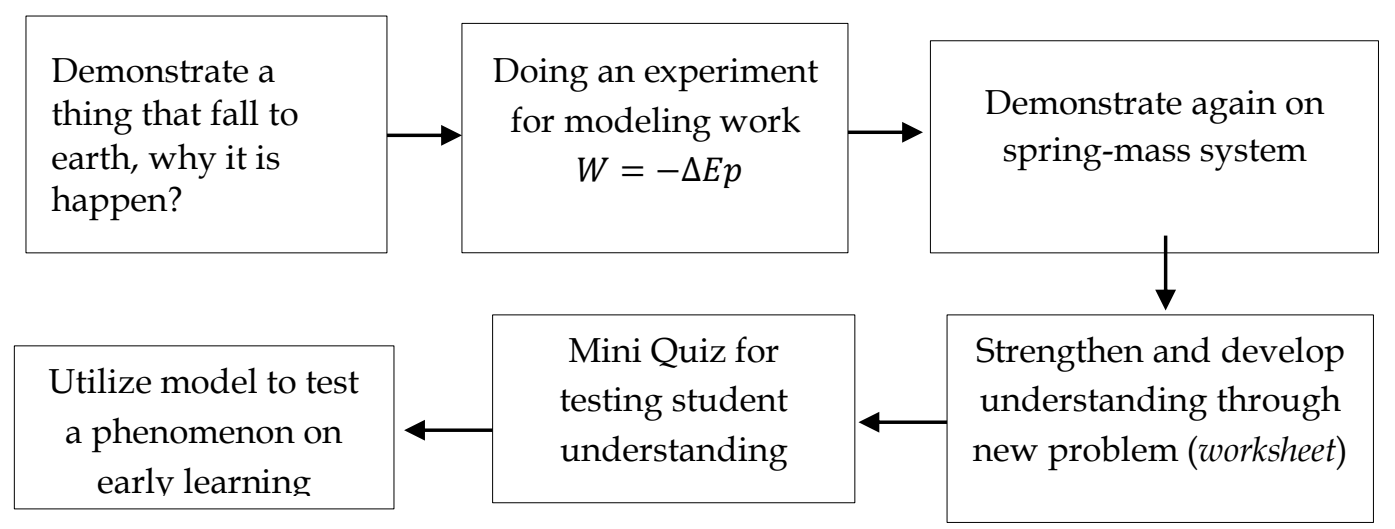

Picture 4. Outline of learning of potential energy system

Through sequence activity in first class, student could create mathematic model of $W=-\Delta E p$. Its means that for moving load (as system) with $\mathrm{m} \mathrm{kg}$ mass and $\mathrm{h}$ meters height from ground need energy as big as $\Delta E p$ or $m g \Delta h$. Learning continued to demonstrate system of spring-mass and discussed a new problem based on worksheet supplemented worked examples. Based on most of group worksheets see on picture 5, appear that student skill of taking important information based on context have increased. 

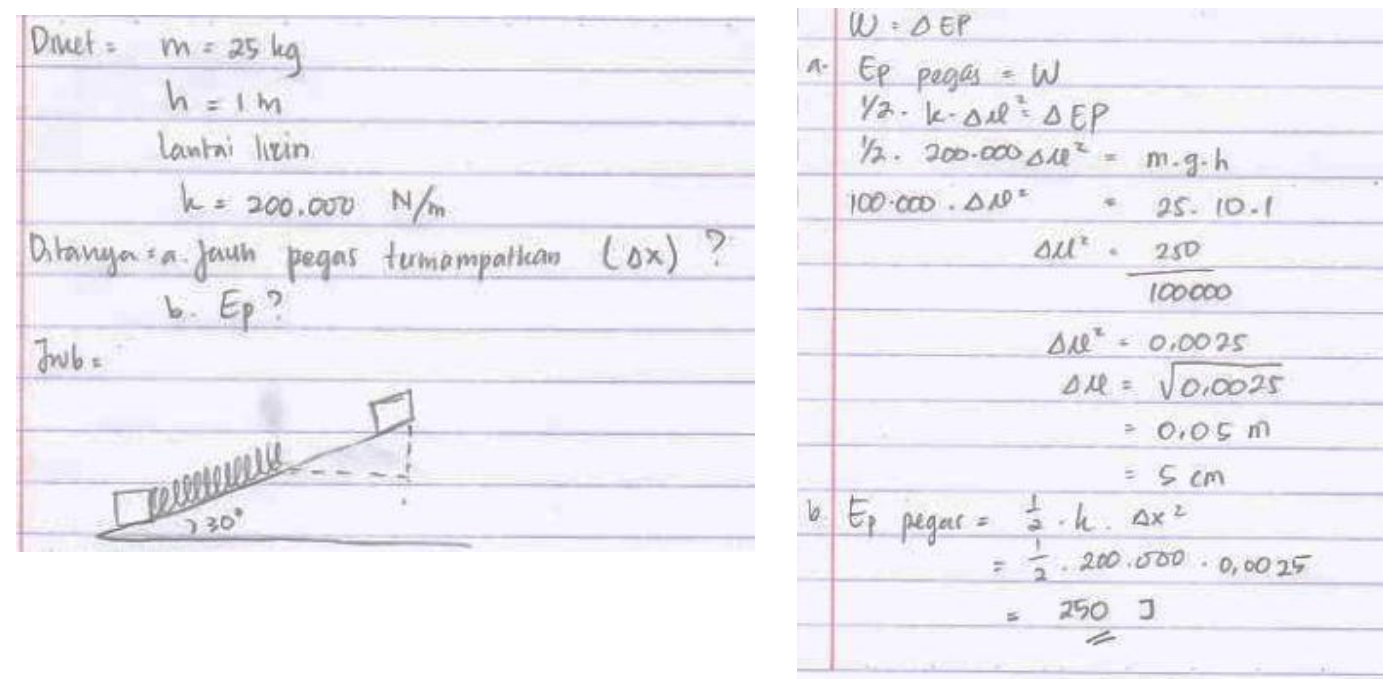

Picture 5. Discussion Result of Most Group of Student (Group 5)

Through students answered can be interpreted that they understand that to find energy of load on inclined plane with $30^{\circ}$ must not describe any force diagram. They also success on determining that potential energy of system depend on changing position. In presentation session they confirmed that potential energy of system that they mean was energy of system (load + spring). Although they did not write it on worksheet, system to which intended was system of two thing. Because it is impossible find potential energy of single object. This concept is corresponding with statement that potential energy only have on system minimum of two objects (Huis \& Berg, 1993; Keeports, 2017). Beside that, students also gave explanation why object fall to earth. They thought that two objects strived to find the minimum potential energy of system.

Based on observation result above, it indicated that on second learning topic of energy, students understanding about system and model of system increase significantly.

\section{Learning of Mechanical Energy Conservation}

The Goal of this learning was to facilitate students finding and applying the law of mechanical energy conservation. Summary of activity can be seen in Picture 6 .

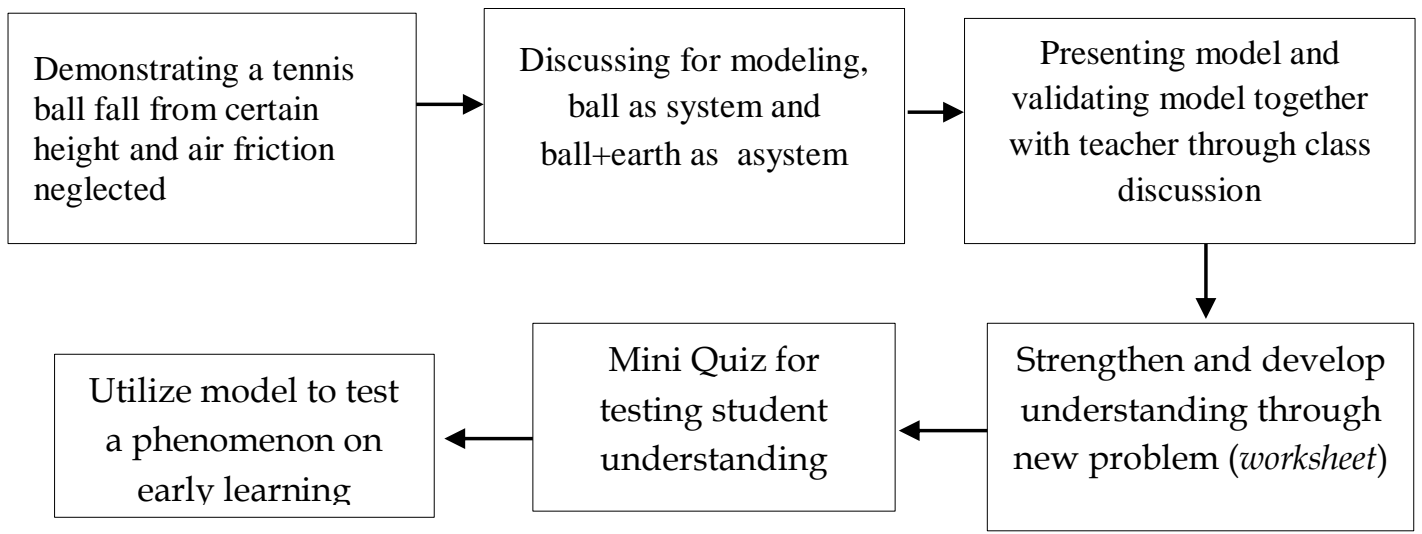

Picture 6. Summary of Student Activity on Learning Topic of Mechanic Energy Conservation 
By discussing on phenomena which demonstrate, most groups could determine the system and model of the system. Group 5 was the group that has a chance to present their model in front of the class. This group succeeds to create two models of the system. (1) ball as the system, earth as the environment (Picture 7a). By choosing this system, they can successfully understand that energy transfer from an environment (earth) to a system (ball) was marked by changing the kinetic energy of a system. Students utilize the concept of work-kinetic energy theorem in first learning to understand the mechanism of energy transfer. In Picture 7b, they choose ball and earth as a system, so that no work from an environment to a system. Effect of choosing ball and earth as system make law of mechanical energy conservation was applied. Changing of potential energy add to the kinetic energy of the system were zero, its mean that no creating energy and no losing energy of a system. Moreover, group 6 explained more clearly with a concept of reaction. When ball and earth were chosen as a system, no environment worked on the system. It was also mean that no reaction between environment and system, so the energy of the system was no change.

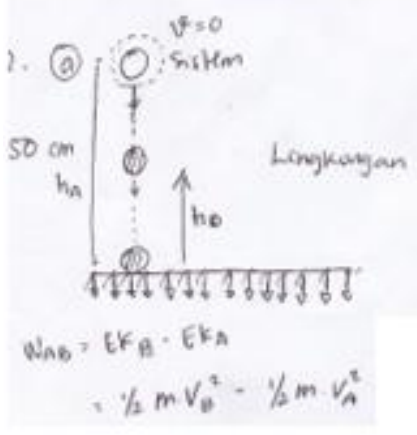

(a)

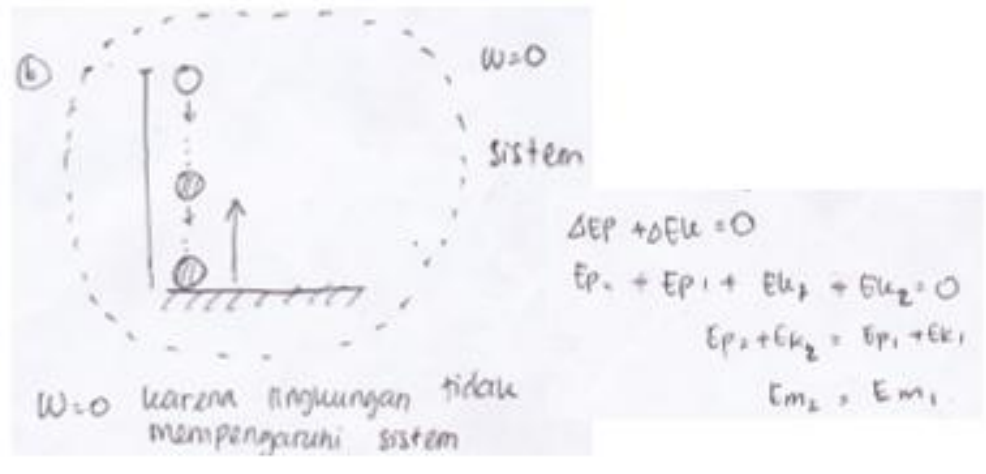

(b)

Picture 7. Modeling system on free fall ball case

After finishing the presentation, every group discussed a problem like first worksheet (Picture 1). One of any group worksheets showed that they have understood the model of conservation energy. They assumed that load A, B, track and earth as a system and no environment. So that no energy transfer between system and environment and law of conservation mechanical energy was applied. Their answer was right perfectly can be seen in Picture 8.

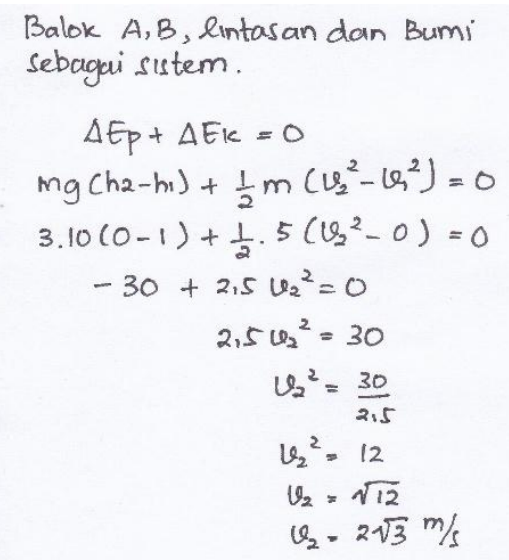

Picture 8. Group Answered (Group 6) 
Based on observation result above, it indicated that on third learning topic of conservation energy, students understanding about system and model of system increase significantly and almost perfectly.

\section{Learning of Mechanism of Energy Transfer Involving Non-Conservative Force}

The focus of fourth learning (1) modified the law of conservation of mechanical energy on a system involving non-conservative force, (2) patterned mechanism of energy transfer happening on the system, and (3) used a model of the mechanism of energy transfer for solving problems involving conservative and non-conservative forces. Summary of student activity on learning in class can be seen in Picture 9.

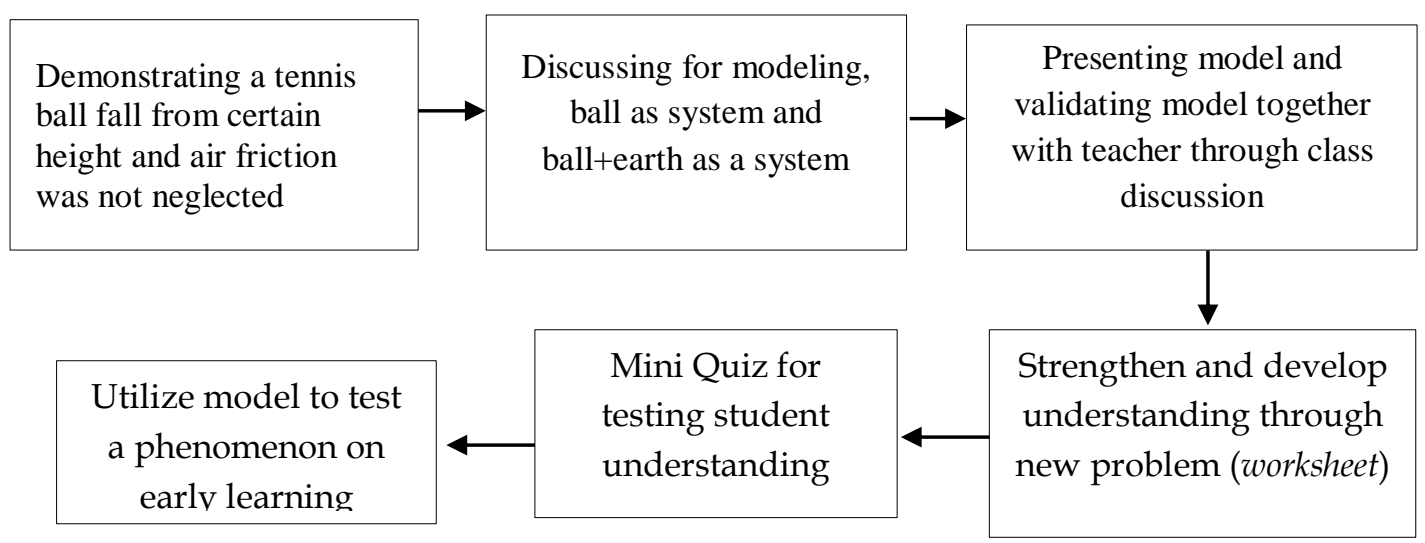

Picture 9. Outline Learning of Mechanism of Energy Transfer

The result of student's discussion showed that while ball, earth, and air as the system, the environment did not impact to system energy. They formulated that the changed of potential energy add to the kinetic energy of system equal to work were done by the non-conservative force on the system.

$$
\Delta E p+\Delta E k=W_{\text {non-konservatif force }}
$$

After success in the modeling of energy transfer, students be given a problem like Picture 1, but between load and floor were rude with 0,25 of friction coefficient. The result indicated that most groups of students had dominated on modeling system.

The result of group 3 discussion chose load A, B as the system, track, and earth as the environment. This group success determined work of each force on load A and B. They used the principal of theorem work-kinetic energy. Through the system, modeling appears that choosing of system impacted to what energy related to a model of the system. This assumption can be seen in line 3 (Picture 10), although they write the equation of $m g h$, they did not mean as potential energy. They interpreted $m g h$ as work of weight force to the system. This interpretation related to Huis \& Berg (1993) that potential energy only had on system minimum of two objects. 


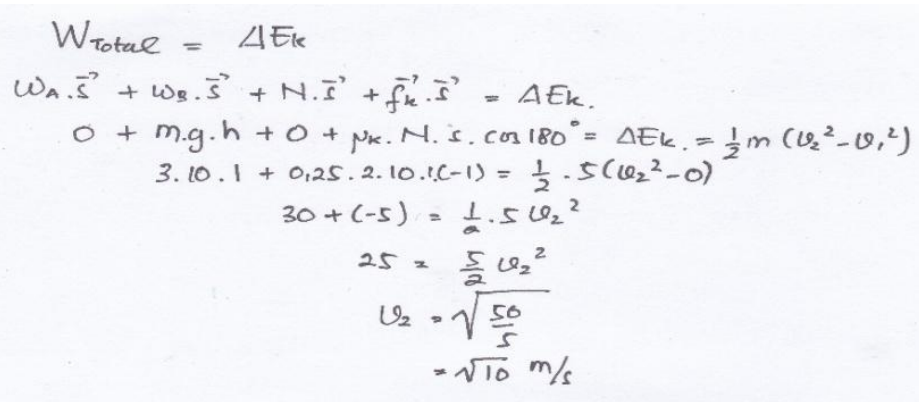

Picture 10. Students Group 3 Answer

The Result of group 5 discussion chose all became system success found the same right answer. They used a model which they found on the development model stage. The result of group 5 can be seen in Picture 11 .

$$
\begin{aligned}
\Delta E_{p}+\Delta E_{k} & =\text { Wgaya non- konservatif } \\
m \cdot g \cdot\left(h_{2}-h_{1}\right)+\frac{1}{2} m\left(U_{2}{ }^{2}-v_{1}{ }^{2}\right)=|\overrightarrow{f k}||\overrightarrow{\mathrm{s}}| \cdot \cos 180^{\circ} & \\
3 \cdot 10(0-1)+\frac{1}{2} \cdot 5 \cdot\left(u_{2}{ }^{2}-0\right)=5 \cdot(-1) & =5 \\
-30+\frac{5}{2} v_{2}{ }^{2} & =-5 \\
\frac{5}{2} v_{2}{ }^{2} & =-5+30 \\
\frac{5}{2} v_{2}{ }^{2} & =25 \\
v_{2}{ }^{2} & =\frac{25 \cdot 2}{5} \\
v_{2}{ }^{2} & =10 \\
U_{2} & =\sqrt{10} \mathrm{~m} / \mathrm{s} .
\end{aligned}
$$

Picture 11. Students Group 5 Answer

On last meeting of modeling instruction learning showed that through this learning, students had successfully increased their skill to determine system and describe system models. Beside it, they also understood what energy related to system chosen. This same meaningful with Halloun \& Hestenes (1987) that model was a carrier messages, different model carried a different message.

\section{Student Understanding of System and Model of System on New Problem After Learning}

The analysis result of increasing of student understanding about system and model of the system on three aspects summarized in Table 1. Amount of data were reduced for obtaining completed data based on the rubric.

Table 1. Summarized of Statistic Descriptive of Increasing Aspect

\begin{tabular}{lcccc}
\hline \multirow{1}{*}{ Aspect } & \multicolumn{4}{c}{ Aspect of rubric } \\
\cline { 2 - 5 } & $\mathrm{RP}$ & $\mathrm{DS}$ & $\mathrm{CS}$ & Total \\
\hline Minimum & 0,00 & 0,11 & 0,00 & 0,04 \\
Maximum & 0,67 & 0,72 & 0,78 & 0,65 \\
Mean & 0,26 & 0,36 & 0,31 & 0,32 \\
Standard Deviation & 0,22 & 0,22 & 0,25 & 0,20 \\
Skewness & 0,23 & 0,27 & 0,18 & 0,08 \\
\hline
\end{tabular}


The average of $\mathrm{N}$-gain on all aspect was 0.32 with a medium category. On aspect of recognizing problem (RP) only 0.26 of $\mathrm{N}$ gain score were a low category. Increasing student skill to recognize and write deep information from question did not increase significantly from pretest to posttest. This deficiency can be more increased by any exercise to recognize contexts. In fact, recognizing skill was a part of qualitative analysis skill that was very important in solving a problem (Docktor \& Mestre, 2014; Walsh et al., 2007). On aspect of determining solution (DS) based on system 0.36 (medium category) score of $\mathrm{N}$-gain were obtained. It means that student skill of choosing system increased significantly enough. The medium increasing of student skill of DS in line with Lin \& Singh (2011) stated that the biggest difficulty of a solving problem was determining what principal chose to solve the problem. On aspect of completing solution score of $\mathrm{N}$-gain 0.32 (medium category) were obtained. The medium increasing of student skill of CS were caused by wrong mathematical procedure and substitution error.

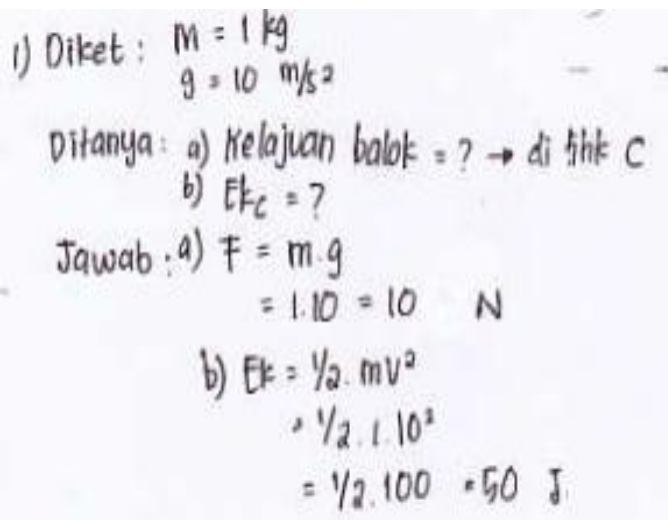

(a)

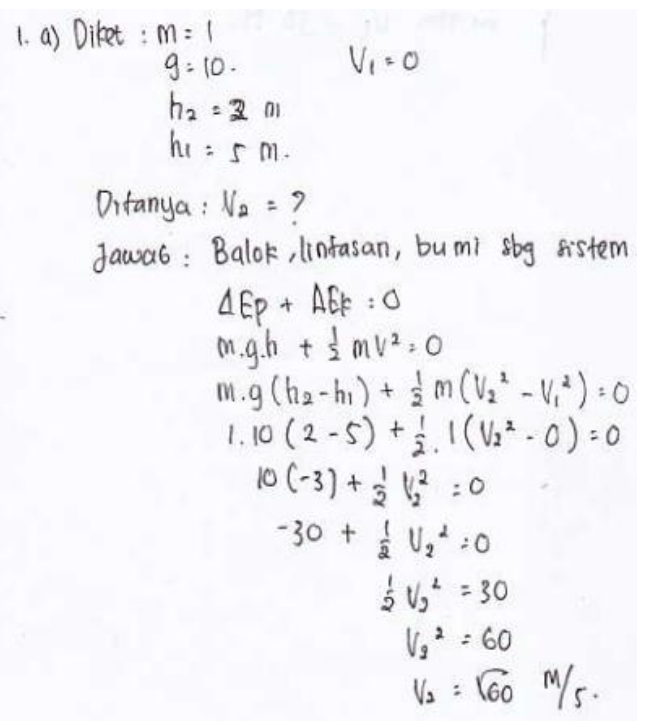

(b)

Picture 12. (a) pretest answer and (b) posttest answer

Changing of student's skill in solving a problem based on the understanding of system and model of the system appeared when they solve the problem. For examples: student number 9 (Picture 12). In the pretest, she used no clear strategy, but in posttest, she used scientific strategy. On posttest, she chose load, track, and earth as a system to make analysis easier. Beginning with identification all implicit and explicit information, she continued to choose system and model it. The last strategy, she did a mathematic procedure and check the answer unit as a variable in physics. Although only 10 students that could solve problem scientifically, it showed that quality of student's skill on solving problem-based system had developed like an expert problem solver (Docktor \& Mestre, 2014; Hegde \& Meera, 2012).The book 


\section{CONCLUSION}

Students understanding of system and model of system increased significantly. Explanation of learning in class showed that on every meeting session, student skill increased from novice to expert. They able to show how important of analysis based on system for explaining mechanism of energy transfer. Average N-gain 0.32 (medium category) indicated that modeling instruction were good enough to promote student understanding of system. Moreover, any misconception about energy were able to prevent and overcome by this learning. By learning, student's skill to solve new problem had changed similar with expert problem solver

\section{BIBLIOGRAPHY}

Akerson, V. L., White, O., Colak, H., \& Pongsanon, K. (2011). Relationships Between Elementary Teachers' Conceptions of Scientific Modeling and the Nature of Science. In M. S. Khine \& I. M. Saleh (Eds.), Models and Modeling (pp. 221-237). Dordrecht: Springer Netherlands. https:/ / doi.org/10.1007/978-94-007-0449-7_10

Arends, R. (2012). Learning to teach (9th ed). Dubuque, Iowa: McGraw-Hill.

Brewe, E., Kramer, L., \& O’Brien, G. (2009). Modeling instruction: Positive attitudinal shifts in introductory physics measured with CLASS. Physical Review Special Topics - Physics Education Research, 5(1). https:/ / doi.org/10.1103/PhysRevSTPER.5.013102

Chi, M. (1989). Self-explanations: How students study and use examples in learning to solve problems. Cognitive Science, 13(2), 145-182. https://doi.org/10.1016/03640213(89)90002-5

Constantinou, C. P., \& Papadouris, N. (2012). Teaching and learning about energy in middle school: an argument for an epistemic approach. Studies in Science Education, 48(2), 161-186. https:/ / doi.org/10.1080/03057267.2012.726528

Dalaglioglu, S., Demirci, N., \& Sekercioglu, A. (2015). Eleventh Grade Students' Difficulties And Misconceptions Baout Energy and Momentum Concept. International Journal on New Trends in Education and Their Implications, 6(1).

Develaki, M. (2016). Key-Aspects of Scientific Modeling Exemplified by School Science Models: Some Units for Teaching Contextualized Scientific Methodology. Interchange, 47(3), 297-327. https:// doi.org/10.1007/s10780-016-9277-7

Docktor, J. L., \& Mestre, J. P. (2014). Synthesis of discipline-based education research in physics. Physical Review Special Topics - Physics Education Research, 10(2). https://doi.org/10.1103/PhysRevSTPER.10.020119

Fakhriyah, F., Masfuah, S., Roysa, M., Rusilowati, A., \& Rahayu, E. S. (2017). Student's Science Literacy in the Aspect of Content Science? Jurnal Pendidikan IPA Indonesia, 6(1). https://doi.org/10.15294/jpii.v6i1.7245

Hake, R. R. (1998). Interactive-engagement versus traditional methods: A six-thousandstudent survey of mechanics test data for introductory physics courses. American Journal of Physics, 66(1), 64-74. https:/ / doi.org/10.1119/1.18809

Halloun, I. A., \& Hestenes, D. (1987). Modeling instruction in mechanics. American Journal of Physics, 55(5), 455-462. https:/ / doi.org/10.1119/1.15130 
Hegde, B., \& Meera, B. N. (2012). How do they solve it? An insight into the learner's approach to the mechanism of physics problem solving. Physical Review Special Topics - Physics Education Research, 8(1). https://doi.org/10.1103/PhysRevSTPER.8.010109

Huis, C. van, \& Berg, E. van den. (1993). Teaching energy: a systems approach. Physics Education, 28(3), 146-153. https:/ / doi.org/10.1088/0031-9120/28/3/003

Jackson, J., Dukerich, L., \& Hestenes, D. (2008). Modeling Instruction: An Effective Model for Science Education. Science Educator, 17(1), 10-17.

Karpin, T., Juuti, K., \& Lavonen, J. (2014). Learning to apply models of materials while explaining their properties. Research in Science E Technological Education, 32(3), 340351. https:/ / doi.org/10.1080/02635143.2014.944494

Keeports, D. (2017). Locating gravitational potential energy. Physics Education, 52(1), 013007. https://doi.org/10.1088/1361-6552/52/1/013007

Lin, S.-Y., \& Singh, C. (2011). Using isomorphic problems to learn introductory physics. Physical Review Special Topics - Physics Education Research, 7(2). https:/ / doi.org/10.1103/PhysRevSTPER.7.020104

Mustofa, Z., Sutopo, \& Mufti, N. (2016). Pemahaman Konsep Siswa SMA Tentang Usaha dan Energi Mekanik (Vol. 1, pp. 519-528). Presented at the Seminar Nasional Pendidikan IPA Pascasarjana UM, Malang: Pascasarjana UM.

National Research Council (U.S.) (Ed.). (2012). A framework for K-12 science education: practices, crosscutting concepts, and core ideas. Washington, D.C: The National Academies Press.

Next Generation Science Standards: For States, By States. (2013). Washington, D.C.: National Academies Press. https://doi.org/10.17226/18290

Ogilvie, C. A. (2009). Changes in students' problem-solving strategies in a course that includes context-rich, multifaceted problems. Physical Review Special Topics Physics Education Research, 5(2). https:/ / doi.org/10.1103/PhysRevSTPER.5.020102

Purwani, L. D., Sudargo, F., \& Surakusumah, W. (2018). Analysis of student's scientific literacy skills through socioscientific issue's test on biodiversity topics. Journal of Physics: Conference Series, 1013, 012019. https://doi.org/10.1088/17426596/1013/1/012019

Slavin, R. E. (2006). Educational psychology: theory and practice (8th ed). Boston: Pearson/Allyn \& Bacon.

Treagust, D. F., Chittleborough, G., \& Mamiala, T. L. (2002). Students' understanding of the role of scientific models in learning science. International Journal of Science Education, 24(4), 357-368. https:/ / doi.org/10.1080/09500690110066485

Walsh, L. N., Howard, R. G., \& Bowe, B. (2007). Phenomenographic study of students' problem solving approaches in physics. Physical Review Special Topics - Physics Education Research, 3(2), pp. 1-31. https://doi.org/10.1103/PhysRevSTPER.3.020108

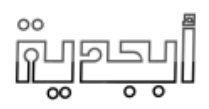

